\title{
Usefulness of Transnasal Ultrathin Endoscopy for the Placement of a Postpyloric Decompression Tube
}

\author{
Hiroki Endo ${ }^{a}$ Masahiko Inamori ${ }^{a}$ Takayuki Murakami ${ }^{b}$ Kenichi Yoshida ${ }^{c}$ \\ Takuma Higurashi $^{a}$ Hiroshi lida $^{a}$ Hirokazu Takahashia $^{a}$ Tomoyuki Akiyama $^{a}$ \\ Keiko Akimoto ${ }^{a}$ Yasunari Sakamoto $^{a}$ Koji Fujita ${ }^{a}$ Masato Yoneda ${ }^{a}$ Yasunobu Abe $^{a}$ \\ Noritoshi Kobayashi $^{\mathrm{a}}$ Kensuke Kubota $^{\mathrm{a}}$ Atsushi Nakajima ${ }^{\mathrm{a}}$ \\ ${ }^{\mathrm{a}}$ Gastroenterology Division, ${ }^{\mathrm{b}}$ Urology and 'Surgery, Yokohama City University School of Medicine, \\ Yokohama, Japan
}

Dear Sir,

A 69-year-old man who had received an operation for prostate carcinoma 1 week previously complained of abdominal pain and vomiting. Abdominal X-ray revealed a dilated jejunum, and we diagnosed him as having ileus. Insertion of a postpyloric decompression tube was necessary. An ultrathin endoscope (GIFN260, outer diameter: $4.9 \mathrm{~mm}$; Olympus) was inserted via the nasal cavity and was used to suction gastric fluids and to advance a guidewire into the duodenum (fig. 1). After withdrawal of the endoscope, a decompression tube was inserted over the guidewire under fluoroscopic guidance.

Postpyloric tubes are now commonly placed under fluoroscopic guidance. However, this procedure requires a longer fluoroscopy time than endoscopy-assisted placements. Transnasal endoscopy can reduce the time required for postpyloric tube intubation for the suctioning of gastric fluids and the advancement of guidewires into the duodenum. Moreover, traditional oral endoscopy methods require oronasal transfer techniques, but transnasal endoscopy can be used to place the postpyloric decompression tube directly. We have confirmed the validity of transnasal ultrathin endoscopy for the placement of postpyloric decompression tubes.

\section{KARGER}

Fax +4161306 1234 E-Mail karger@karger.ch www.karger.com

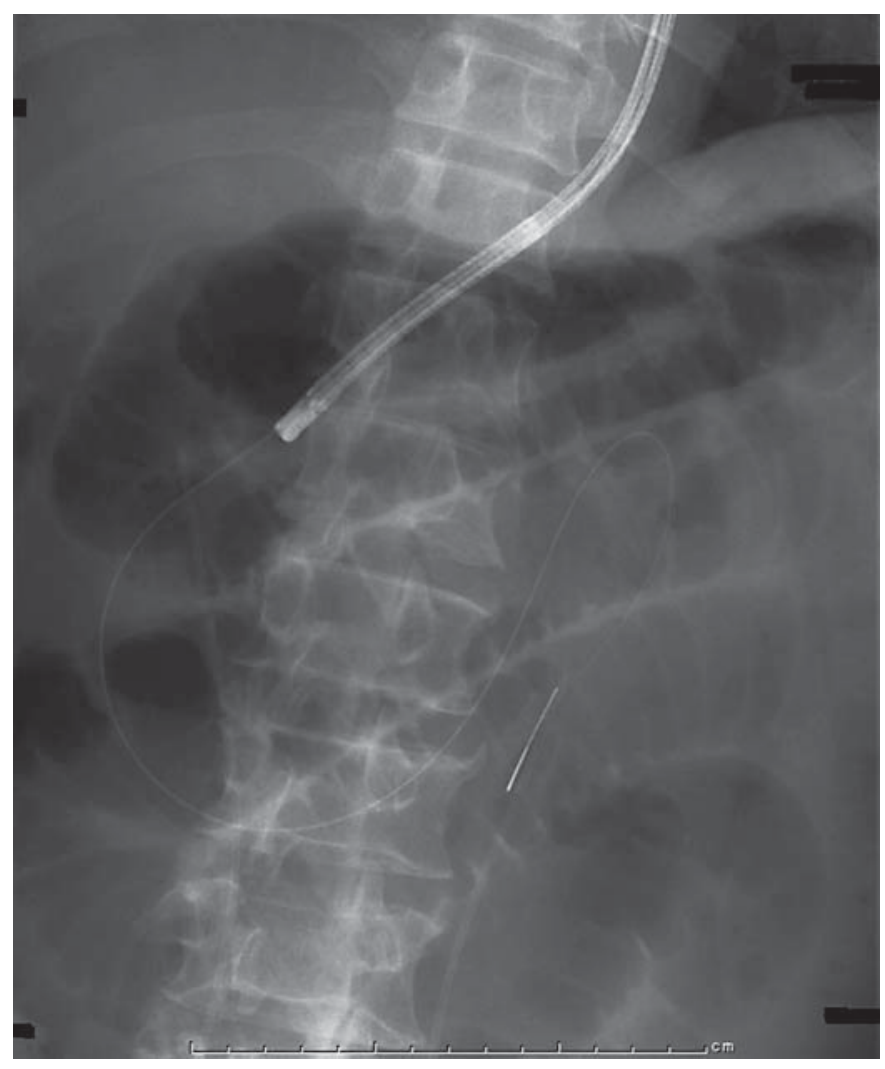

Fig. 1. A transnasal ultrathin endoscope (GIF-N260, outer diameter: $4.9 \mathrm{~mm}$; Olympus) was inserted into the second portion of the duodenum, and a guidewire was placed prior to the insertion of a nasojejunal decompression tube. 